\title{
Planos municipais de saneamento básico
}

por Alceu de Castro Galvão Junior ${ }^{1}$

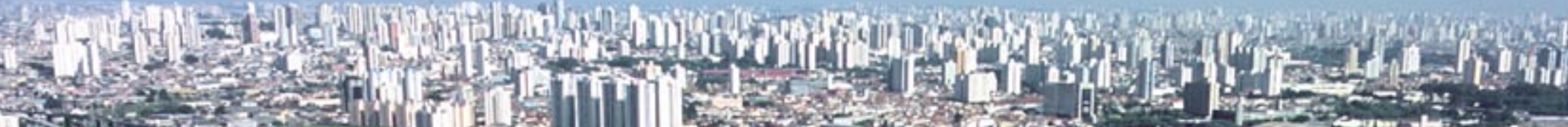

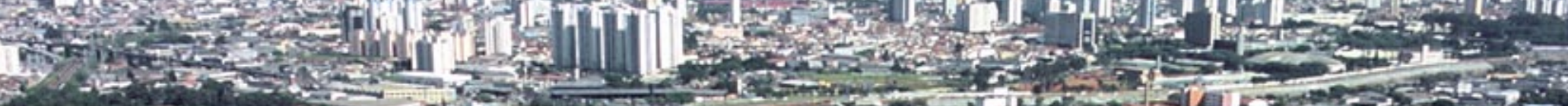

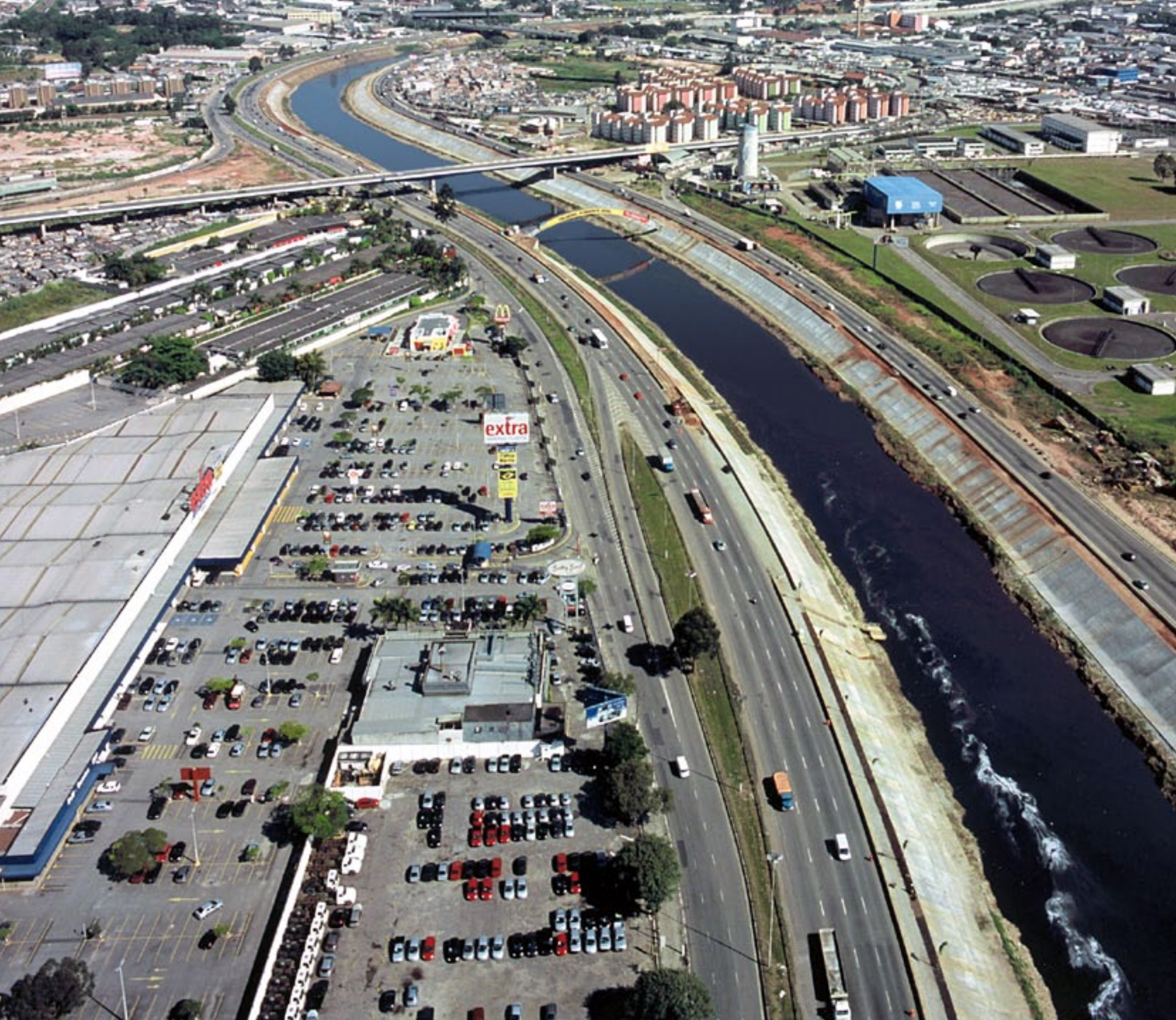




\section{Contexto legal}

A Lei federal $n^{\circ}$ 11.445/2007, conhecida como a Lei de Diretrizes Nacionais de Saneamento Básico (LNSB), regulamentada pelo Decreto federal $n^{\circ} 7.217 / 2010$, estabelece, entre seus princípios fundamentais, a universalização da prestação dos serviços (art. $2^{\circ}$ ). A universalização é conceituada como a ampliação progressiva do acesso de todos os domicílios ocupados ao saneamento básico (art. $3^{\circ}$, inc. III). No contexto do marco regulatório setorial, o saneamento básico é definido (art. $3^{\circ}$, inc. I) como o conjunto de serviços, infraestruturas e instalações operacionais de abastecimento de água, esgotamento sanitário, limpeza urbana e manejo de resíduos sólidos e drenagem urbana.

Para se alcançar o acesso universal aos serviços de saneamento básico, a LNSB estabeleceu vários instrumentos, além de fortalecer outros já existentes, entre os quais, o planejamento, o controle social, a regulação e o exercício da titularidade. Desta forma, a política pública do município deve ser formulada visando à universalização da prestação dos serviços, sendo o Plano Municipal de Saneamento Básico (PMSB) o instrumento de definição de estratégias e de diretrizes.

De acordo com o art. $9^{\circ}$ da LNSB, compete ao município, titular dos serviços, exceto para as Regiões Metropolitanas, em que a titularidade passa a ser comparti- lhada entre estado e municípios, conforme decisão do Supremo Tribunal Federal (STF) na ADI 1.842/RJ, cujo acórdão ainda aguarda publicação, a responsabilidade pela elaboração do PMSB, que deverá ser compatível com os planos de investimentos e os projetos relativos aos contratos de concessão e de programa. Já o art. 11, inc. I, define como condição para a validade dos contratos, a existência do PMSB, bem como expressa a necessidade de estudo de viabilidade técnica e econômico-financeira da prestação universal e integral dos serviços, nos termos do respectivo plano (art. 11, inc. II). Esta medida busca assegurar a exequibilidade da prestação dos serviços em preço compatível com padrão tecnológico adequado, evitando, assim, que sejam estabelecidas metas inexequíveis em relação à realidade da delegação.

Conforme art. 19 da LNSB, o conteúdo mínimo do PMSB deve contemplar:

- Diagnóstico da situação e de seus impactos nas condições de vida, utilizando sistema de indicadores sanitários, epidemiológicos, ambientais e socioeconômicos e apontando as causas das deficiências detectadas;

- Objetivos e metas de curto, médio e longo prazo para a universalização, admitidas soluções graduais e progressivas, observando a compatibilidade com os demais planos setoriais;
- Programas, projetos e ações necessários para atingir os objetivos e as metas, de modo compatível com os respectivos planos plurianuais e com outros planos governamentais correlatos, identificando possiveis fontes de financiamento;

- Ações para emergências e contingências;

- Mecanismos e procedimentos para a avaliação sistemática da eficiência e eficácia das ações programadas.

Com base neste conteúdo mínimo, os municípios devem construir seus planos, desde que observem a compatibilidade com os planos das bacias hidrográficas nas quais estão inseridos (art. 19 , § $3^{\circ}$ ), e o controle social do processo de elaboração, mediante ampla divulgação das propostas dos planos e dos estudos que os fundamentem, inclusive com a realização de audiências ou consultas públicas (art. 19, § 5º). Uma vez elaborados, caberão às entidades reguladoras a verificação do cumprimento dos planos (art. 20, parágrafo único), devendo ser revistos periodicamente, em prazo não superior a 4 (quatro) anos. Assim, o PMSB configura-se como uma ferramenta estratégica de planejamento e de gestão, com vistas a alcançar a melhoria da qualidade e da cobertura dos serviços de saneamento básico, com impactos positivos nas condições ambientais, de saúde e na qualidade de vida da população.

\footnotetext{
${ }^{1}$ Engenheiro Civil/UFC. Mestre em Hidráulica e Saneamento e Doutor em Saúde Pública pela Universidade de São Paulo. Engenheiro de Obras e Projetos da Sabesp (1992-2001). Gerente do setor de Saneamento Básico da Agência Reguladora do Estado do Ceará - ARCE desde 2001. Autor e editor de livros sobre regulação do setor de saneamento básico. Coordenador técnico da elaboração de 50 PMSB no estado do Ceará. Autor do livro "A informação no contexto dos planos de saneamento básico”, editado pela ARCE em parceria com a FUNASA. Coordenador de Planos de Saneamento Básico. Ganhador do Prêmio Jabuti 2012, com o $3^{\circ}$ lugar na categoria Ciências Exatas. Ganhador da distinção de Emérito da Associação Brasileira de Agências de Regulação - ABAR 2013, categoria Academia.

Currículo Lattes: http://lattes.cnpq.br/2901920124488864
} 
Complementarmente às orientações da LNSB, o Decreto $\mathrm{n}^{\circ}$ $7.217 / 2010$ trouxe alguns esclarecimentos quanto às regras para elaboração dos PMSB. Como exemplo, no art. $25, \S 1^{\circ}$, é reforçada a prerrogativa do município de, a seu critério, executar planos específicos para um ou mais desses serviços. Ou seja, o município poderá elaborar seu Plano, apenas para os componentes abastecimento de água e esgotamento sanitário, para em uma etapa posterior, executar o Plano específico dos componentes de limpeza urbana e manejo de resíduos sólidos e drenagem urbana. Além disso, este Decreto $n^{\circ} 7.217 / 2010$ torna possível, ao titular, receber apoio técnico ou financeiro de outros entes da Federação, do prestador dos serviços ou de instituições universitárias e de pesquisa científica. Vale ressaltar no Decreto que a alocação de recursos públicos federais e os financiamentos com recursos da União serão realizados em conformidade com os Planos de Saneamento, daí a importância dos mesmos serem elaborados com base em critérios técnicos e adequados à realidade a ser transformada. Cabe destacar que, o art. 26 do Decreto, vincula, a partir do ano de 2014, o acesso de recursos públicos federais orçamentários ou financiados à existência de PMSB. Portanto, o Plano de Saneamento se reveste de suma importância para o município, pois, além de vinculante para a celebração de contratos, terá seus investimentos direcionados para a universalização dos serviços.

Outro aspecto relevante na LNSB, notadamente para as Companhias Estaduais de Saneamento Básico (CESBs), é a prestação regionalizada dos serviços, cuja característica deverá atender aos seguintes requisitos (art. 14):

I - um único prestador do serviço para vários Municípios, contíguos ou não;

II - uniformidade de fiscalização e regulação dos serviços, inclusive de sua remuneração;

III - compatibilidade de planejamento.

De forma geral, observa-se que a maioria das CESBs atende ao art. 14 , incs. I e II, porém, para o cumprimento do inc. III, é necessário que os planos tenham uma abrangência regional, garantindo assim um dos pilares de sustentação destas companhias, que é a utilização de subsídios cruzados com uniformidade na cobrança. Assim, sem a prestação regionalizada, as CESBs não estão legalmente amparadas quanto à cobrança uniforme de tarifas, havendo riscos para o sistema de subsídios cruzados e para a sustentabilidade da maioria dos municípios operados.

Oportuno falar do art. 17 da LNSB, que também pode ser aplicável como solução para o tratamento da Região Metropolitana.

Art. 17. O serviço regionalizado de saneamento básico poderá obedecer a plano de saneamento básico elaborado para o conjunto de Municípios atendidos.

Lembrando que esse plano regional não necessita englobar integralmente os territórios dos municípios, exigência imposta para o PMSB no art. 19 , § $8^{\circ}$. Trata-se de solução que se compatibiliza com a autonomia dos entes federados envolvidos, concentrando-se os esforços regionais em áreas de interesse comum.

\section{Questões relevantes para o PMSB}

Objetivamente, o PMSB consiste de duas partes: diagnóstico e prognóstico. A experiência re- cente na elaboração de planos tem demonstrado que alguns pontos carecem de aprofundamento, no sentido de não comprometer os reais objetivos do planejamento, que é a universalização dos serviços de saneamento básico. Tais aspectos estão relacionados com: a informação como fator limitante na elaboração do PMSB; a interface com o planejamento estabelecido na Política Nacional de Resíduos Sólidos; a definição das unidades de planejamento e o tratamento das áreas urbanas e rurais; a uniformidade dos indicadores que expressam as metas de universalização; os sistemas de informações; e a regulação da prestação dos serviços.

\section{A Informação como Fator Limi- tante na Elaboração do PMSB}

O principal fator limitante para a elaboração dos PMSB é a informação, considerada insumo básico para o planejamento e a regulação dos serviços. Tendo em vista o caráter monopolista do setor de saneamento básico e a forte assimetria de informações entre prestadores e demais atores do setor, os dados relativos à prestação, em geral, não se encontram acessíveis aos formuladores dos planos, e quando disponível, sua qualidade é precária. Desta forma, somente os prestadores de serviços conhecem com profundidade a qualidade de seus produtos e serviços, suas despesas, investimentos e dados operacionais, entre outros, necessários para a montagem do plano. Tal situação dificulta o processo de elaboração do plano de saneamento, e, no limite, pode, inclusive, comprometer a sua qualidade.

Por outro lado, a disponibilidade de informações relativas aos indicadores sanitários, epidemiológicos, ambientais e socio- 
econômicos, é ampla e acessível de forma gratuita na internet, em diversos bancos de dados, como o Datasus, IBGE, Portal da Transparência, entre outros.

Apesar da limitação da informação, notadamente as relacionadas à prestação dos serviços, sua aquisição por si só não é suficiente para que se faça um Plano de Saneamento adequado. As informações devem ser tratadas na forma de indicadores, comparadas a situações regionais e estaduais, bem como avaliadas em termos de comportamento ao longo dos últimos anos, para que se possam estabelecer metas condizentes com as reais necessidades da população e com a disponibilidade de recursos financeiros para o seu cumprimento.

Interface com a Política Nacional de Resíduos Sólidos (PNRS) - Lei $n^{\circ}$ 12.305/2010

Adicionalmente a exigência dos Planos de Saneamento na LNSB, a PNRS obriga os titulares de serviços a elaborarem seus Planos Municipais de Gestão Integrada dos Resíduos Sólidos (PMGIRS), cujo conteúdo mínimo deve observar as exigências do art. 19 da referida política. No tocante a componente resíduos sólidos, enquanto que o PMSB (Lei $n^{\circ}$ 11.445/2007) foca na limpeza urbana e no manejo de resíduos sólidos, o PMGIRS (Lei $\left.n^{\circ} 12.305 / 2010\right)$ incorpora outros tipos de resíduos como os da construção civil, serviços de saúde, agrossilvopastoris, entre outros. Para que o município não tenha que fazer dois planos (PMSB e PMGIRS), a Lei $n^{\circ}$ 12.305/2010 permite que $o$ plano municipal de gestão integrada de resíduos sóli- dos pode estar inserido no plano de saneamento básico previsto no art. 19 da Lei $n^{\circ} 11.445$, de 2007 , respeitado o conteúdo mínimo previsto nos incisos do caput (art. 19 , § $\left.1^{\circ}, P N R S\right)$.

Portanto, no caso da elaboração do PMSB para os quatros componentes, é recomendável inserir o PMGIRS dentro do PMSB e, assim, cumprir também com as determinações da Lei $n^{\circ}$ 12.305/2010. A elaboração dos dois planos em um só instrumento, além de apresentar ganhos de escala e de escopo, reduzindo os custos de execução, também contribui para uma visão sistêmica da gestão integrada dos resíduos sólidos, haja vista que diversos instrumentos estabelecidos pela PNRS, notadamente a logística reversa, são transversais ao manejo de resíduos sólidos, objeto do PMSB.

\section{Unidades de Planejamento - Áreas Urbanas e Rurais}

De acordo com o art. 19, $\S 8^{\circ}$, da LNSB, o plano de saneamento básico deverá englobar integralmente o território do ente da Federação que o elaborou. Ou seja, deverá compreender as sedes distritais, as localidades urbanas e rurais e a população difusa. Com efeito, o déficit do saneamento se concentra nas periferias das cidades, nas comunidades distantes dos centros urbanos, na população rural e difusa, para onde os programas, projetos e ações do PMSB devem ser priorizados. $\mathrm{O}$ problema é como diagnosticar esta população haja vista que, em geral, não há nestas áreas sistemas ou serviços formais de saneamento básico. Ao analisar 22 PMSB oriundos das cinco regiões do país (2011), Basílio Sobrinho $(2011)^{2}$ concluiu existir dificuldades para se definir explicitamente a unidade territorial de análise e planejamento, haja vista que 14 (quatorze) planos não o fizeram. Além disto, 8 (oito) planos não observaram a abrangência da integralidade do território municipal exigida pela LNSB, contemplando apenas as zonas urbanas.

Desta forma, ao definir as unidades de planejamento, o gestor dever mapear o município em termos de distritos, localidades e população difusa, conforme demonstrado na Figura 1, para posteriormente estabelecer uma linha de corte, em termos de quantidade mínima de habitantes por localidade a ser diagnosticada. Já as aglomerações urbanas ou rurais com população inferior a linha de corte, deverão ser tratadas como população difusa. Porém, esta realidade não é válida para os grandes centros urbanos, que não apresentam população rural ou difusa em seus territórios.

\section{Uniformidade dos Indicadores}

Independentemente da localização geográfica ou porte do município, os indicadores das metas de universalização devem ser uniformes. Com isto, haverá possibilidade de se construir sistemas de comparação de indicadores, permitindo ainda ações de coordenação regional e nacional acerca da evolução da universalização.

Porém, a uniformidade dos indicadores não significa que, em função de particularidades locais e regionais, o município não possa ter seus próprios indicadores específicos, mas isso se configura como situação de exceção. Com

\footnotetext{
${ }^{2}$ BASILIO SOBRINHO, G. Instrumento Para Universalização Do Abastecimento de Água e do Esgotamento Sanitário. 2011.112 p. Dissertação (Mestre em Engenharia Civil) - Universidade Federal do Ceará, Fortaleza.
} 


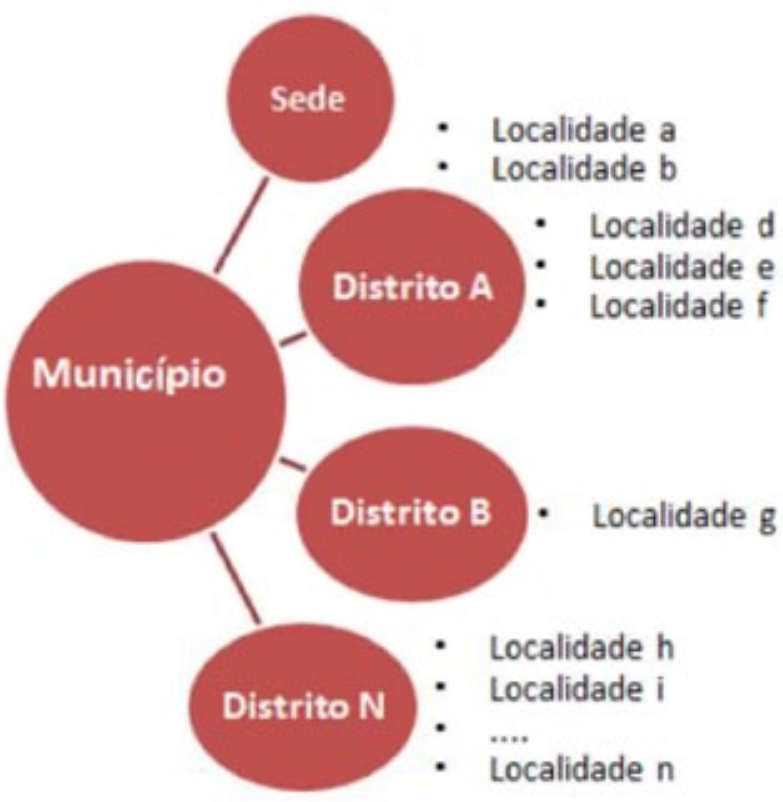

\section{+ População Difusa}

Figura 1- definição das áreas de planejamento

efeito, é importante, por exemplo, que o indicador de perdas adotado no estado do Amapá, seja o mesmo daquele adotado para os municípios de São Paulo, e que todos eles, tenham o mesmo conceito utilizado pelo Sistema Nacional de Informações sobre Saneamento (SNIS). O que irá diferenciar cada município, em termos de indicadores, é o dimensionamento da meta e os prazos para alcançá-la, mais ou menos agressivos, a depender da viabilidade econômico-financeira de cada delegação.

Outro aspecto relevante no tocante à uniformidade dos indicadores, diz respeito à gestão por parte de uma CESB, caso cada uma de suas delegações venha a definir para um determinado indicador, um conceito diferente. $\mathrm{O}$ mesmo raciocínio se aplica a uma agência reguladora estadual, responsável pelo acompanhamento de dezenas, ou até mesmo, centenas de planos, cujos serviços são operados por uma CESB. A Figura 2 caricatura esta situa- ção para o Estado de São Paulo, onde, em uma situação extrema, cada município operado pela Sabesp adotaria em seu plano de saneamento um conceito de

indicador de perdas diferente, comprometendo assim a gestão do plano por parte da própria Sabesp, e seu acompanhamento por parte da Arsesp.

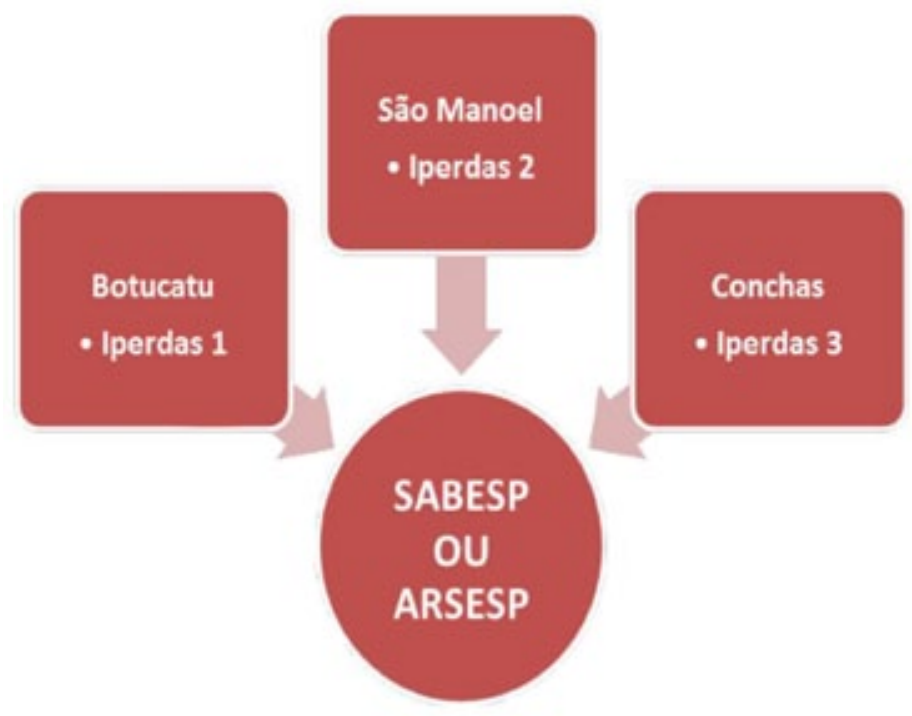

Figura 2- situação hipotética de falta de uniformidade nos indicadores para o plano de saneamento 
A solução para este problema é o estabelecimento de um painel recomendativo de indicadores para Planos de Saneamento, elaborado com base no SNIS. Proposta neste sentido foi apresentada em estudos desenvolvidos por Galvão Junior et al, $2012^{3}$.

\section{Valor Global dos Investimentos para a Universalização}

O Plano Nacional de Saneamento (Plansab) estima que, para a universalização dos serviços de saneamento básico no país, são necessários investimentos da ordem de $\mathrm{R} \$ 508,5$ bilhões até o ano de 2033, havendo uma previsão específica destes recursos a ser investida em cada estado. Outra forma de calcular o valor necessário para a universalização nos estados é somar os investimentos de todos os PMSB. Com efeito, esta última forma se aproxima mais da realidade, haja vista que no Plano foram mensurados todos os investimentos necessários à universalização do saneamento básico em termos de programas, projetos e ações.

Este assunto foi levantado pela Agência Reguladora Intermunicipal de Saneamento (ARIS), ao avaliar o conjunto de PMSB já elaborados em Santa Catarina e projetar o valor total dos investimentos para o estado, concluindo-se que o volume de recursos previstos eram superiores àqueles informados no Plansab. Entre as conclusões do referido estudo, destacam-se:

No estudo ora apresentado chama a atenção o volume de recursos que a Casan deverá aportar nos próximos 25 anos $(R \$ 9,1$ bi-
Ihões), recursos estes que deverão ser buscados através da economia gerada pela melhor prestação dos serviços públicos e de recursos onerosos (empréstimos). Há que se exigir um Plano de Investimento por parte da CASAN, para cada município abrangido pela mesma, para que se permita o acompanhamento dos investimentos ao longo do tempo.

É preciso que os Municípios e o Governo do Estado trabalhem de forma mais aprofundada e dedicada nas ações e no planejamento do saneamento em Santa Catarina. Em alguns casos, as tarifas praticadas não cobrem os investimentos necessários, em decorrência das peculiaridades locais (baixa densidade populacional, topografia, nível de renda, etc).

Vale ressaltar que a Casan não participou de forma efetiva da elaboração dos PMSB em Santa Catarina e dos estudos de viabilidade econômico-financeira, porém seus contratos deverão ser pautados nesses instrumentos. Assim, pode-se mencionar a regra do art. $19, \S 6^{\circ}$, que não dispensa o cumprimento pelo prestador do respectivo plano de saneamento básico em vigor, com possibilidade de revisão tarifária nos casos de delegações pré-existentes.

Como aprendizado para os demais prestadores de serviços, sugere-se que esses acompanhem pari-passo a elaboração de todos os PMSB em seus municípios operados, no sentido de evitar que se aprovem Planos eventualmente desfocados com a realidade econômico-financeira das delegações e dos próprios estados.

\section{Sistemas de Informação}

O $9^{\circ}$, caput, inc. VI, da LNSB prevê o estabelecimento de sistema de informações sobre os serviços, articulado com o Sistema Nacional de Informações em Saneamento Básico (Sinisa), sucessor do SNIS. Já o art. $2^{\circ}$, caput, inc. IX da mesma lei, define a transparência das ações como princípio fundamental dos serviços, baseada inclusive em sistemas de informações. Além disto, outros artigos da LNSB versam sobre a necessidade de sistema de informações para o acompanhamento dos índices de qualidade e serviços prestados, bem como das ações estabelecidas no PMSB.

O principal fator a ser considerado para a implantação de um sistema de informações baseado em indicadores de desempenho é a organização e a estrutura do prestador de serviços, que certamente será a principal fonte de dados para a alimentação do sistema, ou do titular, quando este presta diretamente os serviços. O sistema de informações é uma ferramenta de gestão integrada, com foco no acompanhamento dos programas, projetos e ações do Plano, que apresenta interfaces para cadastro e manipulação de dados, além de consultas e análises posteriores, por meio de indicadores.

Considerando a necessidade de integração dos dados e a utilização destes como instrumento de tomada de decisões nos planos regional e estadual, é necessário que cada estado organize seu sistema, integrado ao Sinisa, e com acesso aos atores setoriais, notadamente os reguladores, responsáveis pela

${ }^{3}$ GALVÃO JUNIOR, A. C.; BASílio SOBRINHO, G; CAETANO, A. C. Painel De Indicadores Para Planos De Saneamento Básico. In: PHILIPPI JR, A.; GALVÃO JR, A. C. (Eds.). Gestão Do Saneamento Básico: Abastecimento De Água e Esgotamento Sanitário. Barueri-SP: Manole, 2012, p.1040-68. (Coleção ambiental). 
verificação do cumprimento dos planos. Ademais, considerando a fragilidade organizacional e técnica da maioria dos municípios brasileiros, um sistema com base regional e/ou estadual pode viabilizar sua implantação em função dos ganhos de escala e de escopo.

\section{Regulação}

A regulação tem, como finalidade, proteger o interesse público, com vistas ao atendimento dos princípios e das diretrizes que orientam a formulação e a condução das políticas públicas. $\mathrm{O}$ art. 11, inc. III, da LNSB estabelece a regulação como condição vinculante para a validade dos contratos de prestação dos serviços de saneamento básico, devendo a mesma ser realizada em atendimento aos seguintes princípios (art. 21):

I. independência decisória, incluindo autonomia administrativa, orçamentária e financeira da entidade reguladora;

II. transparência, tecnicidade, celeridade e objetividade das decisões.

Constituem ainda, objetivos da regulação definidos na LNSB (art. 22):

I - estabelecer padrões e normas para a adequada prestação dos serviços e para a satisfação dos usuários;

II - garantir o cumprimento das condições e das metas estabelecidas;

III - prevenir e reprimir o abuso do poder econômico, ressalvada a competência dos órgãos integrantes do sistema nacional de defesa da concorrência, e

$I V$ - definir tarifas que assegurem tanto o equilíbrio econômico e financeiro dos contratos como a modicidade tarifária, mediante mecanismos que induzam à eficiência e eficácia dos serviços e que permitam a apropriação social dos ganhos de produtividade.

No tocante aos Planos de Saneamento Básico, a interface entre a regulação e o planejamento é explicitada no art. 20, parágrafo único, da LNSB, que define as atribuições específicas da entidade reguladora:

Incumbe à entidade reguladora e fiscalizadora dos serviços a verificação do cumprimento dos planos de saneamento por parte dos prestadores de serviços, na forma das disposições legais, regulamentares e contratuais.

Porém, de acordo com a pesquisa Regulação 20134, da Associação Brasileira de Agências de Regulação (ABAR), cerca de 49\% municípios são regulados no país. Portanto, além de elaborar os planos, outro desafio que se coloca para o setor é a constituição e a estruturação de entidades reguladoras. Conforme demonstrado na Figura 3, a evolução da regulação no país tem se comportado de maneira lenta, em função da complexidade de se instituir e, principalmente, de operacionalizar uma agência reguladora.

\section{Custo do PMSB}

O cenário institucional do setor de saneamento, com elevados níveis de investimento em infraestrutura, objeto do Programa de Aceleração do Crescimento (PAC), vem mobilizando grande parte da capacidade técnica instalada no país, e causando impactos no processo de elaboração dos planos, em função dos seguintes fatores:

- Aquecimento do mercado da engenharia, com baixa disponibilidade de mão-de-obra qualificada;

- Demanda elevada por Planos em função da necessidade de regularização de contratos (prestadores de serviços) e de captação de recursos (titulares);

- Prazo final para elaboração dos Planos até dezembro de 2013;

- Recursos escassos para financiamento da elaboração dos Planos por parte da União;

- Baixa capacidade técnica dos

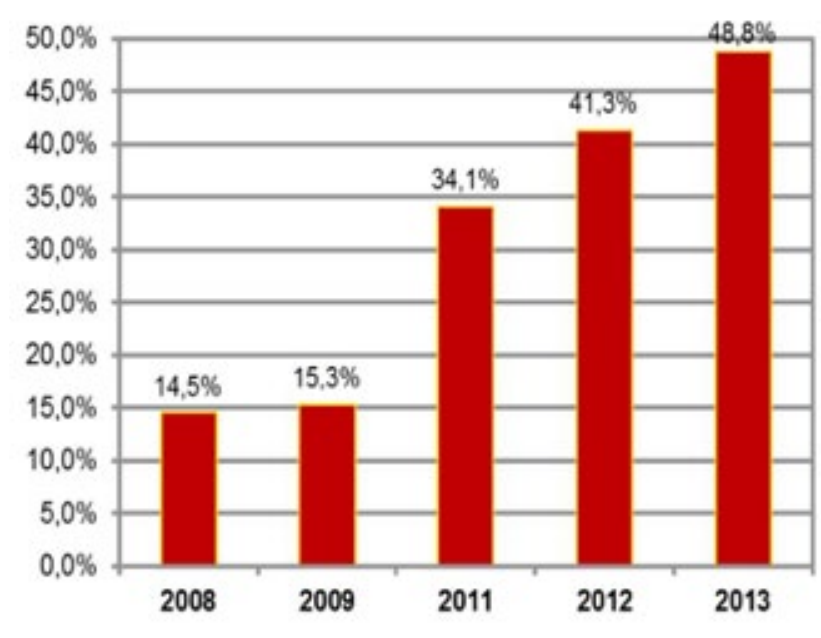

Figura 3- Evolução dos municípios regulados no Brasil

\footnotetext{
${ }^{4}$ Associação Brasileira de Agências de Regulação - ABAR. Saneamento Básico: Regulação 2013. Brasília, 2013.
} 
titulares para elaboração do Plano com recursos humanos próprios.

Em função disto, tem-se observado aumento considerável nos custos para elaboração dos Planos, que pode variar de $\mathrm{R} \$ 2$ a $\mathrm{R} \$ 15$ por habitante, tornando-se proibitivo para a maioria dos municípios.

Vale ressaltar que o PMSB pode ser elaborado diretamente pela municipalidade, por meio de seu próprio quadro técnico. Dentro deste contexto, a LNSB e seu decreto regulamentador consideraram a possibilidade de apoio técnico e financeiro por parte dos prestadores de serviços e de outros atores setoriais, conforme observado anteriormente. Devido a essa possibilidade, distintas formas de elaboração desses planos municipais vêm emergindo, seja por meio de parcerias com universidades e com empresas de consultoria, ou através do fomento ou atuação indireta do prestador de serviços.

Assim, diante dos elevados valores de elaboração dos Planos e da precariedade da gestão setorial por parte dos municípios, torna-se imprescindivel buscar alternativas para redução de custos que, ao mesmo tempo, incorpore a cultura do planejamento no quadro técnico dos titulares e dos próprios prestadores de serviços, e preserve a qualidade técnica nos termos da LNSB. Desta forma, são listadas a seguir diversas formas de execução dos PMSB.

a) Cooperação Técnica entre Prestador de Serviços e Municípios, por meio de sua Associação, com contratação de consultoria especializada, ou via Convênio com Universidades, modelos utilizados no estado do Amazonas e no Ceará;

b) Construção de Plano de Referência para elaboração do PMSB pelo próprio município, com publicação de um Guia para elaboração do PMSB, agregado a um Plano Matriz (Plano de Referência) para preenchimento por parte do município, o qual teriam seus técnicos capacitados; e no modelo tradicional, via

c) Contratação de Consultoria.

\section{Estágio atual}

Não há números oficiais de quantos PMSB já foram elaborados, entretanto, segundo a $\mathrm{ABAR}^{5}$, estima-se que no máximo 34\% dos municípios brasileiros disponham de seus planos, com base em uma amostra de 2.716 municípios (Figura 4). Considerando ainda a representatividade desta pesquisa, que engloba os principais estados do país, exceto o Paraná, é razoável supor que no máximo se tenha entre $25 \%$ e $30 \%$ do total de municípios do país com seus planos concluídos.

Já a Tabela 1 (página 14) mostra os resultados da pesquisa ABAR, por estado e por agência reguladora.

\section{Situação pós-plano}

Com efeito, a principal dificuldade para a elaboração do plano é a falta de capacidade de gestão do município no tocante ao saneamento básico. Faltam quadros técnicos e estrutura administrativa até para discutir questões técnicas dos planos quando de sua elaboração. De acordo com a Tabela 2 (página 15), com a pesquisa Munic 2011 do IBGE, dos 5.565 municípios brasileiros, somente em 30\% deles há estrutura na área de gestão do saneamento.

Uma das formas de minimizar este aspecto é aprovar o PMSB por lei, criando-se instrumentos básicos para a gestão do Plano. Além disso, a aprovação por lei

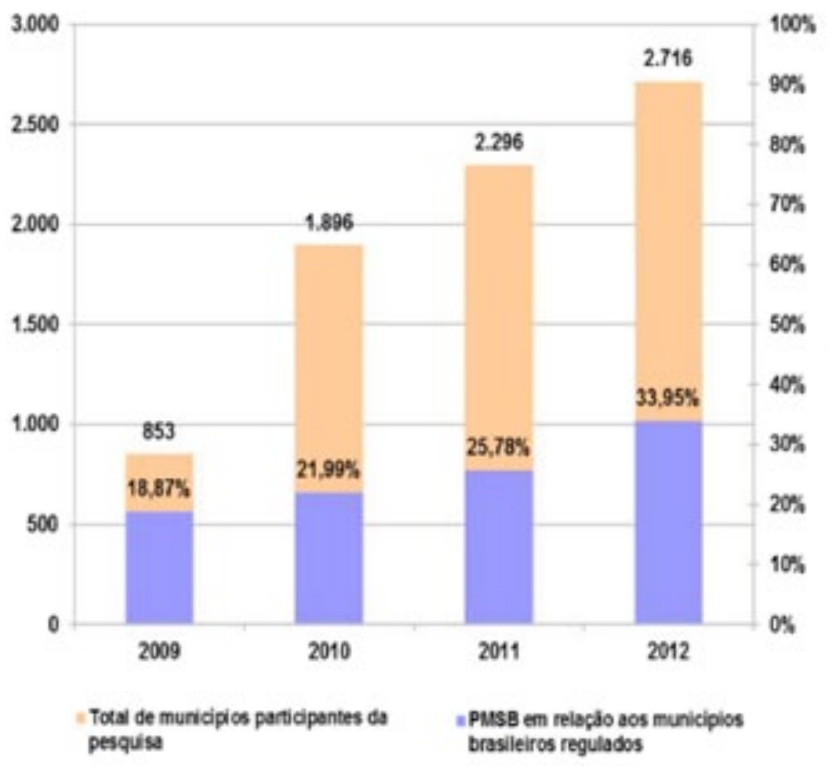

Figura 4- Municípios regulados com PMSB

${ }^{5}$ Associação Brasileira de Agências de Regulação - ABAR: Regulação 2013. 


\begin{tabular}{|c|c|c|c|}
\hline Estado & Agência & $\begin{array}{l}\text { Municípios } \\
\text { Regulados }\end{array}$ & $\begin{array}{l}\text { Quant. de } \\
\text { Planos }\end{array}$ \\
\hline $\mathrm{AL}$ & ARSAL & 25 & 24 \\
\hline$A M$ & ARSAM & 1 & 0 \\
\hline BA & AGERSA & 364 & 8 \\
\hline CE & ARCE & 150 & 21 \\
\hline DF & ADASA & 1 & 0 \\
\hline ES & ARSI (E) e AGERSA (M) & 12 & 3 \\
\hline GO & AGR & 225 & 21 \\
\hline MG & ARSAE & 628 & 152 \\
\hline MS & AGEPAN & 40 & 0 \\
\hline MT & AMAES (M) & 1 & 1 \\
\hline PA & ARCON & 4 & 0 \\
\hline PB & ARPB & 190 & 0 \\
\hline $\mathrm{PE}$ & ARPE & 171 & 18 \\
\hline PI & ARSETE $(M)$ & 1 & 0 \\
\hline RJ & AGENERSA & 8 & 0 \\
\hline $\mathrm{RN}$ & ARSBAN (M) & 1 & 0 \\
\hline RS & AGERGS & 246 & 113 \\
\hline SC & AGESAN (E), AGR (M), AMAE (M), AGIR (C) e ARIS (C) & 294 & 292 \\
\hline SP & ARSESP (E), ARSAEG (M) e ARES-PCJ (C) & 302 & 269 \\
\hline TO & ATR & 52 & 0 \\
\hline TOTAL & 27 & 2.716 & 922 \\
\hline
\end{tabular}

(M) Agência reguladora municipal; (E) Agência reguladora estadual; (C) Agência reguladora consorciada. As demais agências não indicadas são estaduais.

Fonte: ABAR, 2013

Tabela 1- PMSB por estado em municípios regulados

minimiza riscos para o operador, caso os serviços delegados sejam prestados por meio de contrato, haja vista que as metas deste instrumento devem estar associadas às metas do plano de saneamento.

Diante do exposto, a lei que instituir o plano deve conter, no mínimo, os seguintes aspectos: a aprovação do plano, cujo conteúdo é um anexo da própria lei; a definição do órgão responsável pela administração do plano no âmbito da prefeitura municipal; a definição do órgão respon- sável pelo controle social, em geral delegado a um conselho municipal já existente, como de meio ambiente ou da saúde; e, por fim, a definição da entidade reguladora, responsável pelo acompanhamento da execução do PMSB. Dessa forma, ficará 


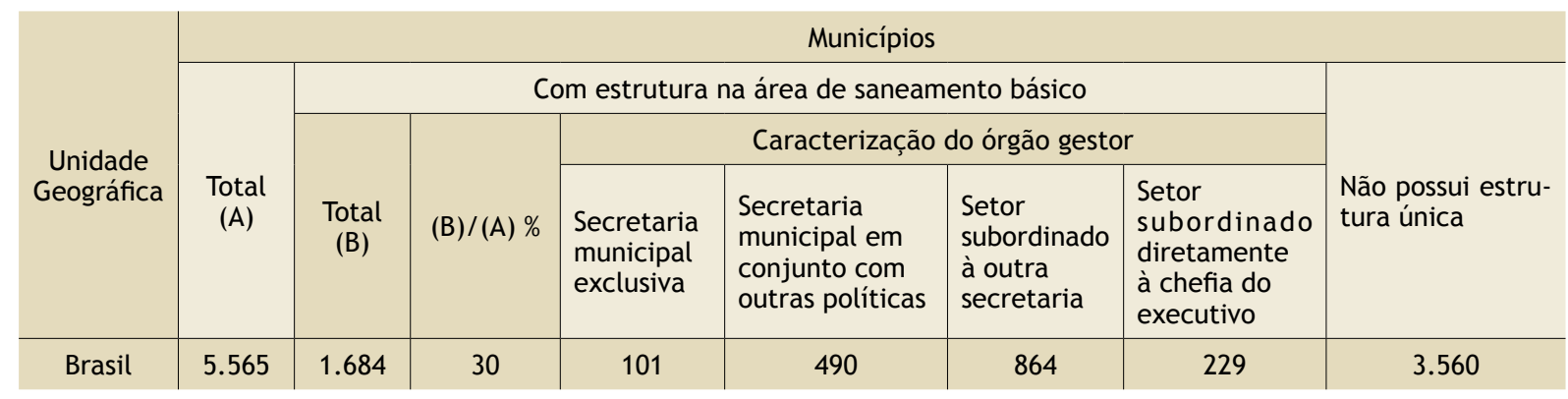

Fonte: IBGE, Pesquisa Munic 2011, Tabela 108

Tabela 2- Municípios com estrutura na área de saneamento básico, por caracterização do órgão gestor, ano 2011

consolidado por lei o tripé com as funções da titularidade (órgão administrativo municipal), do controle social (designação do conselho municipal) e da regulação (agência reguladora).

Porém, somente a lei não é suficiente para garantir a sustentabilidade do Plano. É necessária uma articulação de todas as esferas, no sentido de se constituir instrumentos de apoio técnico permanente aos municípios. Neste contexto, experiência recente no Estado do Ceará, foi iniciada por meio da realização de cursos para formação de administradores de Planos, e mediante cooperação técnica entre universidades e municípios, para suporte a execução dos programas, projetos e ações dos PMSB.

Desafios para o setor em relação ao planejamento

Considerando o baixo percentual de Planos finalizados e os prazos para conclusão dos PMSB (dezembro de 2013), a escolha de alternativas para elaboração dos Planos deve considerar as seguintes premissas:

- Soluções que envolvam a participação das Associações dos Municípios no processo de coordenação, objetivando melhorar o nível de mobilização e participação dos municípios, além de contribuir para colocar o saneamento básico na agenda política desses entes;

- Priorização da elaboração dos PMSB dos municípios de menor porte, e que não disponham de recursos financeiros e humanos;

- Foco na elaboração de Planos dos municípios com investimentos previstos para o curto prazo e cuja captação de recursos dependa da existência do PMSB;

- Elaboração conjunta dos PMSB no âmbito regional, facilitando a execução no curto e médio prazo dos Planos Regionais (prestação regionalizada);

- Permita a visão do conjunto de investimentos em todas as delegações operadas pelo Prestador Estadual, com vistas à viabilidade econômica e financeira da empresa no médio e longo prazo;

- Possibilite a padronização de instrumentos de planejamento, notadamente indicadores de acompanhamento das metas dos programas, projetos e ações;

- Permita a apropriação do conhecimento por parte do quadro técnico dos municípios e do próprio Prestador Estadual; além de auxiliar na criação de uma cultura de planejamento setorial no estado.

Por fim, são listados os principais desafios do setor em relação ao planejamento, a saber:

- Universalização da prestação dos serviços em municípios onde não há viabilidade econômico-financeira, notadamente nas áreas rurais;

- Garantir fonte de recursos para financiar a universalização dos serviços de saneamento básico;

- Criar mecanismos de subsídios para acesso da população sem capacidade de pagamento aos serviços de saneamento básico;

- Realizar a gestão dos planos municipais de saneamento básico, haja vista que a maioria dos municípios não dispõe de equipes técnicas;

- Rever os contratos de concessão assinados entre os municípios antes da Lei dos Consórcios.

Desta forma, o setor e a sociedade terão efetivos instrumentos de planejamento que contribuirão para a tão sonhada universalização da prestação dos serviços. 